\title{
An outline of extension from Neutrosophic Psychology to Pneumatic Transpersonal Psychology: Towards Relational Psychotherapy and Relational Pedagogy
}

\author{
Victor Christianto ${ }^{1}$, Florentin Smarandache ${ }^{2}$ \\ ${ }^{1}$ Satyabhakti Advanced School of Theology - Jakarta Chapter, Jakarta, Indonesia. \\ ${ }^{2}$ Dept. Mathematics and Sciences, University of New Mexico, Gallup - USA. Email: \\ florentin.smarandache@laposte.net
}

\begin{abstract}
Continuing our previous paper, we gave an outline of a new integral model of human consciousness scheme beyond Freudian mental model. We start from a recent book by one of us: Neutropsychic personality. Then we discuss possibility to reintroduce spirit into human consciousness. To emphasize what we have outlined in a preceding paper, we consider the following: that human consciousness model should take into consideration "spirit" role, i.e. the mind-body-spirit as integral aspect, which view is neglected in the Freudian mental model. In this paper, we consider a further step: introducing "soul" as a different element of human consciousness. We also discuss a few possible applications of such an integral model of human consciousness, including relational psychotherapy and relational pedagogy. While we are fully aware that much remain to be done and we admit that this is only a sketch, we hope that this paper will start a fresh approach of research towards more realistic nonlinear human consciousness model.
\end{abstract}

"The easiest kind of relationship is with ten thousand people, the hardest is with one." - Joan Baez

\section{Introduction}

The present paper grew out of a new book that one of us, FS, recently wrote, with title: Neutropsychic personality.[17] In that book, FS described possible extension of Freudian mental model: id-ego-superego, using his Neutrosophic Logic theory. See also [2][3].

Later on, we thought that it would be necessary to push the boundary one step further, by considering a more realistic way to go beyond that classic Freudian mental model, i.e. by reintroducing the spirit into human consciousness model. We are aware 
that many researchers have proposed such an extension, especially Italian tradition which was continually developed by students of Carl Jung, such as Assagioli and Piere Ferrucci, namely the Psychosynthesis movement.

In our previous paper, see ref. [1], we discussed a new integral view of human consciousness beyond Freudian mental model. Among other things, we consider the following: that human consciousness model should take into consideration "spirit" role, i.e. the mind-body-spirit as integral aspect, which view is neglected in the so-called Freudian mental model. [1]

And in this paper, we consider a further extension to previous triune model, by taking into account the role of "soul". And we also consider a few implications of such an integral view of human consciousness, including relational therapy.

First of all, we will review early years of psychoanalysis.

Part A: Basic Principles

\section{A review of early years of psychoanalysis theory}

Four figures in early years of psychoanalysis are discussed here, with a theme we kept in mind, i.e. in order to show that despite early development not focusing on human spirit, further development of psychoanalysis theories were going to include spirit as central tenets in psychology studies:

a. Pierre Janet

Pierre Janet, in full Pierre-Marie-Félix Janet, (born May 30, 1859, Paris, Francedied February 24, 1947, Paris), French psychologist and neurologist influential in bringing about in France and the United States a connection between academic psychology and the clinical treatment of mental illnesses.

He stressed psychological factors in hypnosis and contributed to the modern concept of mental and emotional disorders involving anxiety, phobias, and other abnormal behavior. Janet's report (1882) of an unusual case of hypnosis and clairvoyance gained him the attention of neurologist Jean-Martin Charcot. As a 
Ph.D. candidate at the University of Paris, Janet studied automatic acts, and in his thesis (1889), which went into many editions, he introduced but did not amplify the concept of the unconscious. This work engendered a later dispute with Sigmund Freud over priority. At Charcot's invitation, Janet became director of the psychological laboratory at the largest Paris mental institution, the Salpêtrière Hospital (1889). ${ }^{183}$

Pierre Janet's therapeutic approach to traumatized patients was the first attempt to create a systematic, phase-oriented treatment of post-traumatic stress. Janet viewed the trauma response basically as a disorder of memory which interfered with effective action, see [36].

Carl Jung, on the other hand, took much of Janet's work, while developing analytical psychology, and added some of the spiritual aspects that Janet had denied. Ultimately, Janet was not successful in explaining the true nature of the psychological phenomena he studied, never resolving his personal struggle between the scientific (focusing on external, observable phenomena) and religious (focusing on internal, spiritual experiences) approaches to understanding life. ${ }^{184}$

b. Sigmund Freud Fundamental to the debate between Janet and Freud were their views on nonconscious processes. Initially there were a number of similarities, but they diverged early, Janet developing a more structural model based on lateral splitting of the psyche, and Freud the more familiar depth model with vertical division.[35]

Furthermore, the term 'ego' originated in the mid- 19th century and by way of Freud became a cornerstone of western psychiatry. He proposed further subdivision into a tripartite structure to include the super-ego and the id. Subdivision of the self also had a long ancestry, particularly in regard to subselves and multiple personality. The origins of modern self-psychology are to be found in the contributions of a group of psychiatric researchers prior to World War I. [35]

\footnotetext{
183 https://www.britannica.com/biography/Pierre-Janet

${ }^{184} \mathrm{http}: / /$ www.newworldencyclopedia.org/p/index.php?title=Pierre_Janet
} 
c. Carl Jung

Carl Gustav Jung (1875-1961) had a significant contribution to the psychoanalytical movement and is generally considered as the prototype of the dissident through the impact of his scission and the amplification of the movement he created in his turn (analytical psychology). In 1902-1903 he attended a traineeship in Paris with Pierre Janet, and then returned to Zurich and he was called senior physician at Burgholzli. It was in this context that Jung was introduced to Freud in 1907. Freud would be seduced by the prestige and personality of Jung and would soon see in him the spiritual son that could ensure the survival of psychoanalysis, so much so as Jung was not Jewish. ${ }^{185}$ Intense, professional and friendship bonds form between the two, with an ambivalence dominated by the inclination of Jung to underestimate himself in comparison with Freud, the fervor of his devotion to the "father" of psychoanalysis and oneiric hostility (emphasized by Freud in the common interpretation of dreams). Jung had a swift ascension in the hierarchy of psychoanalysis. He became the editor of Jahrbuch.

In 1908, he traveled to the United States and in 1910 he became the first president of the International Association of Psychoanalysis. ${ }^{186}$ Since 1912 he became more and more distant in his writings, which would cause a scission materialized in 1914 by his resignation from all the positions he already held. By abandoning the meanders of psychosexuality, Jung would establish himself in the fields of spirituality and esoteric science. ${ }^{187}$

Jung, originally a follower of Freud, split from Freud in 1913, primarily because he believed that Freud presented a reductive view of human nature that left out transpersonal potentialities. Following the split, Jung began to formulate ideas that helped to explain transpersonal experiences and the possibility of transpersonal development; see [38].

\footnotetext{
185 https://www.carl-jung.net/biography.html

${ }^{186} \mathrm{https}: / /$ www.carl-jung.net/biography.html

${ }^{187}$ https://www.carl-jung.net/biography.html
} 


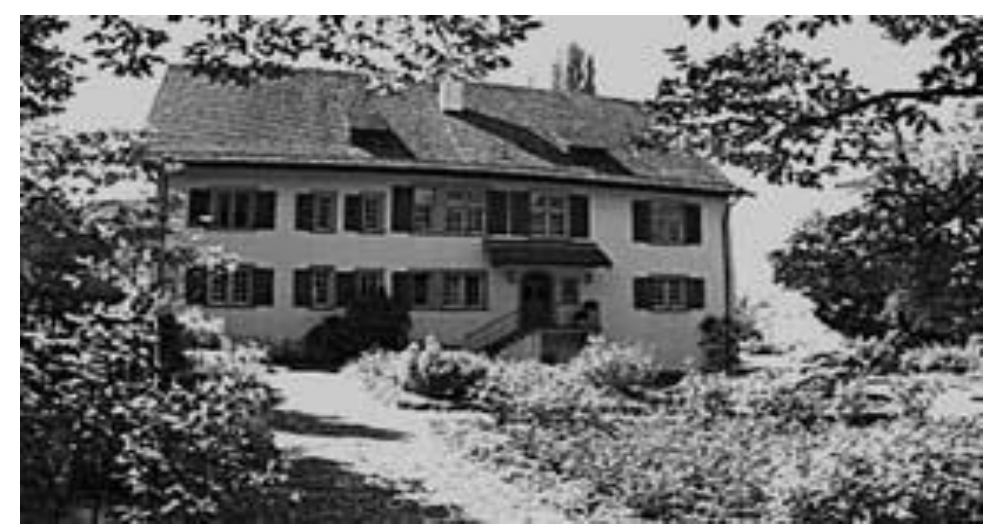

Figure 1. Jung Institut in Kusnacht, Zurich. ${ }^{188}$

d. Roberto Assagioli

Roberto Assagioli (1888-1974) was the first in Italy to adhere to the Freudian movement, although he soon began to pursue his own course. A near contemporary of Carl Gustav Jung (1875-1961), Assagioli embraced the emerging dynamic psychology of that period and developed it into a multilevel integrative vision of the human being, which he called "psychosynthesis." In developing both the theory and practice of psychosynthesis, Assagioli contributed to the history of psychology by showing how dynamic and analytical psychology on the one hand and humanistic and transpersonal psychology on the other might be brought into synthesis. [38] Initially a follower of Freud and psychoanalysis, Assagioli, along with Jung, was a pioneer of what later became known as transpersonal psychology. He had already begun exploring transpersonal themes before the official creation of psychosynthesis (Assagioli, 1927). In the 1960s he was one of the founders of the new field of transpersonal psychology and with Abraham Maslow played an important role both in giving the name "transpersonal" to the field and in bringing attention to important transpersonal concepts such as those of a higher or transpersonal unconscious, "peak experiences" (Maslow, 1962), and a transpersonal Self (Assagioli, 1973b). See [38].

Both Assagioli and Jung drew on Western philosophy, spirituality, and psychology. Assagioli particularly looked at Platonic and Judeo-Christian traditions and existentialism. Both were interested in occult (Jung, 1902) and

${ }^{188}$ https://www.carl-jung.net/biography.html 
parapsychological phenomena (Assagioli, 1976, 11.1-15, 75; 76; 77). However, Assagioli's general approach was pragmatic, practical, and synthetic and was directed towards benefits for society through transpersonal development in education and psychotherapy and through the practice of interpersonal and social psychosynthesis. As Jung drew inspiration from physicists, Assagioli drew inspiration from Eastern teachings, especially teachings on energy systems and energetic fields. He named psycho-energetics a fifth force of psychology after the fourth (transpersonal), and he explored its potential for future development (Assagioli, 1973c). See [38].

In conclusion, Assagioli's view on spirituality differed from Jung's by focusing on a more direct and experiential approach. Assagioli specifically proposed meditations of various types as effective ways to achieve greater awareness, integration, and grounding in the transpersonal (Assagioli, 1963a; 1963b). Similarities, however, exist with the Jungian approach to analysis, symbolic imagery work, and creative-expressive methods. Both men emphasized the importance of the psychotherapeutic relationship as a vehicle for healing, in particular through transference-countertransference dynamics and through the living experience of the transpersonal dimension in human relationships. See [38].

\section{Our contribution: From Neutrosophic Psychology toward integral model of human consciousness}

One of us, FS, recently published a new book, with title: Neutropsychic personality.[17] In that book, FS described possible extension of Freudian mental model: id-egosuperego, using his Neutrosophic Logic theory. See also [2][3].

He wrote among other things:

"Neutropsyche is the psychological theory that studies the soul or spirit using the neutrosophy and neutrosohic theories. In other words: Neutrosophic Psychological Theory. It is based on triadic neutrosophic psychological concepts of the form $(<A>$, $<$ neutA $>$, <antiA $>$ ). Neutropsychic Personality is a neutrosophic dynamic open psychological system of tendencies to feel, think, and act specific to each individual..."[17] 
He goes on to develop a number of implications of this approach, including a model of human memory as follows:

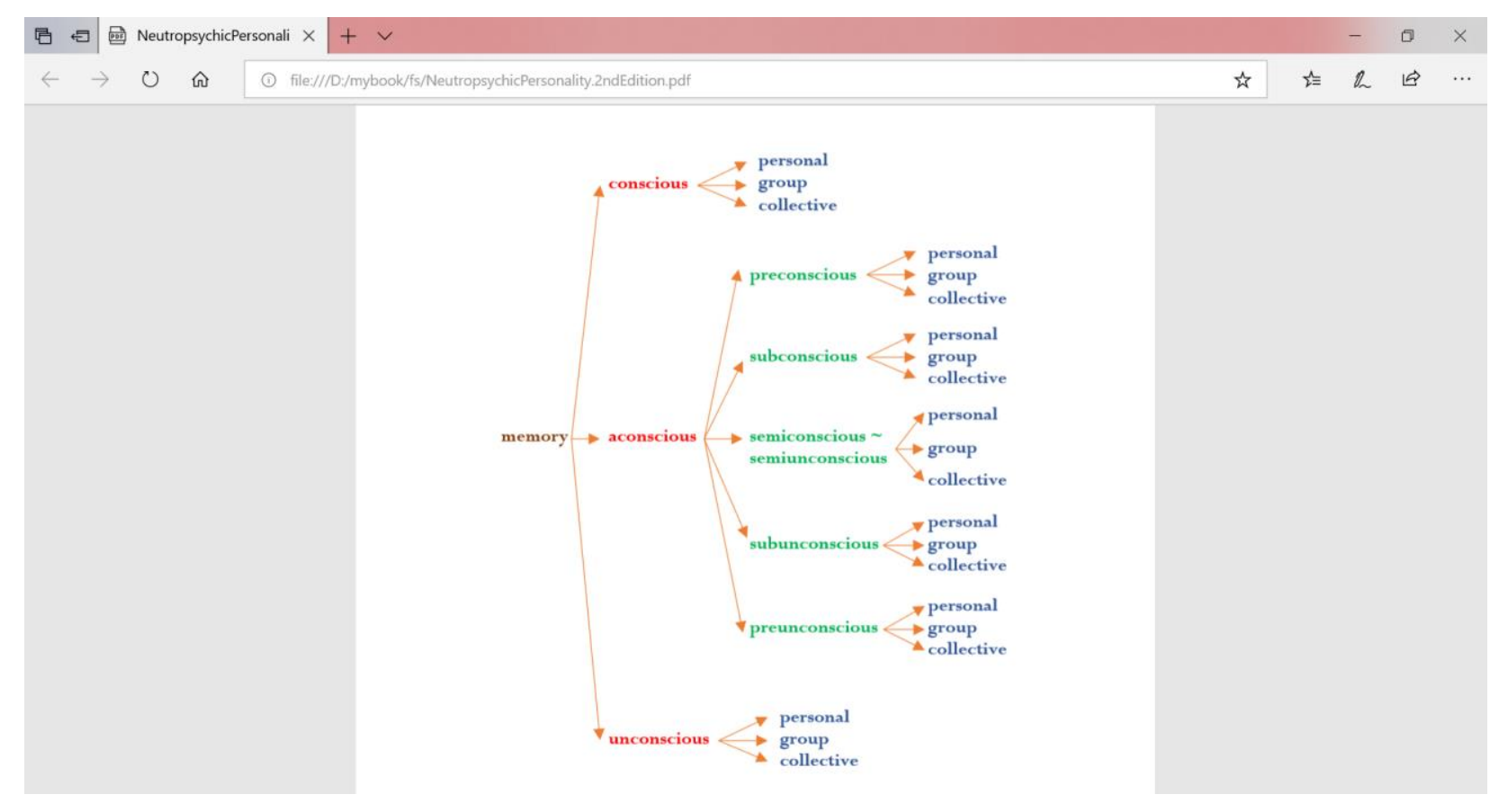

Figure 2. A model of human consciousness based on Neutrosophic Psychology (refined Neutrosophic memory). After F. Smarandache [17, p.41]

But it is not our intention to discuss human memory model in this paper, this topic is reserved for future investigation.

From more discussion on FS's book, we thought that it would be necessary to push the boundary one step further, by considering a more realistic way to go beyond that classic Freudian mental model, i.e. by reintroducing the spirit into human consciousness model. We all know that Hebrew's thought on human being is integral, i.e. the wholeness of body-mind-spirit. But now we shall face the question: how can we come up with a model of human consciousness based on the Bible?

As a starting point, let us begin by the Greatest Commandments:

Matthew 22:37-40 King James Version (KJV)

${ }^{37}$ Jesus said unto him, Thou shalt love the Lord thy God with all thy heart, and with all thy soul, and with all thy mind.

38 This is the first and great commandment. 
${ }^{39}$ And the second is like unto it, Thou shalt love thy neighbour as thyself.

40 On these two commandments hang all the law and the prophets.

Our re-reading of the above commandments lead us to model a Trinitarian dialogue within human self: God, self, and others. ${ }^{189}$

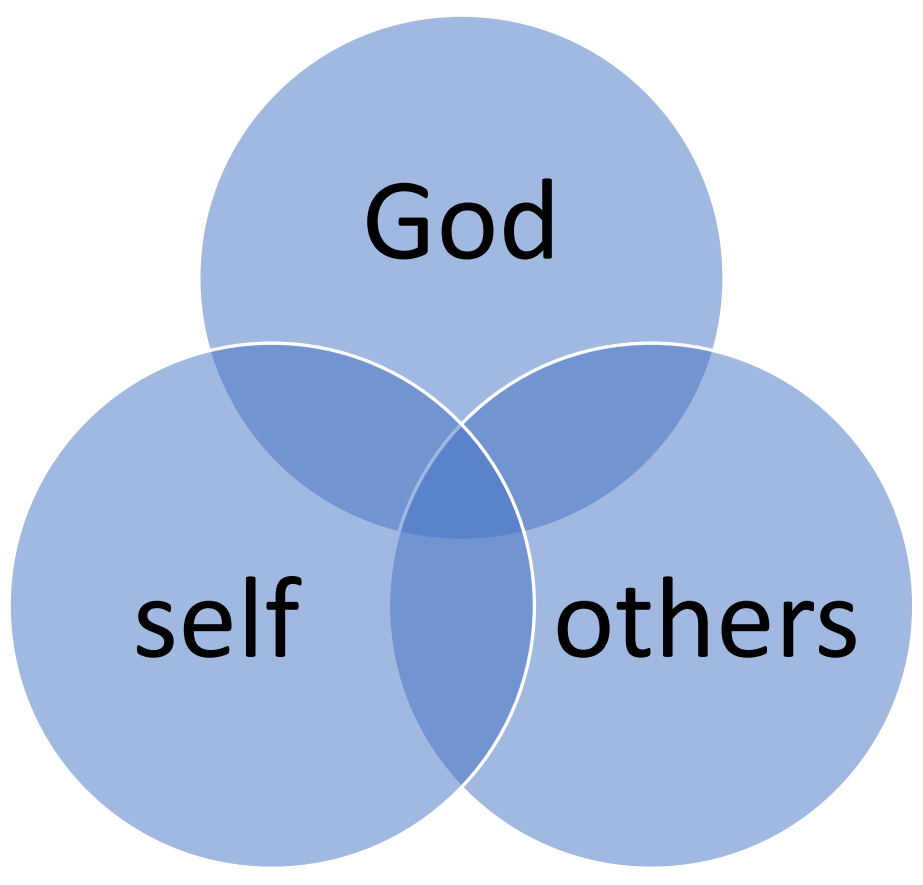

Figure 3. Three directions of human love based on The Greatest Commandments in Matthew 22:37-40.

Comparing with Adam Grant's give and take model of human basic tensions inside our mind. Let us consider parallels, i.e. "taking" reflects selfishness/greediness motive of ego, and "giving" reflects altruism motive of conscience.

In other words, now we have two entities in human consciousness: ego and conscience. There is always deep tension between ego and consciousness, between selfishness and altruism. Along these two poles, we need a third entity which has purpose to ease and being intermediary between these two motives. In this problem, along with

\footnotetext{
${ }^{189}$ For an alternative reading of Mat. 22, see Vern Poythress's article: https://frame-poythress.org/the-greatestcommandment-the-very-heart-of-the-matter/
} 
Neutrosophic Logic [2],190 allow us to submit wholeheartedly that the third entity, is actually no other than "the spirit." (pneuma in Greek, ruach in Hebrew)

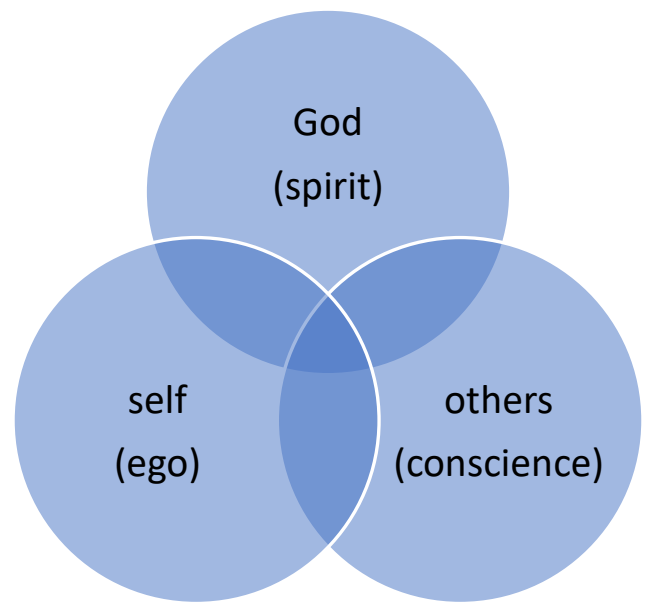

Figure 4. A model of human consciousness based on Greatest Commandments in Matthew 22:37-40.191

The exact role of human spirit is to enlighten both ego and conscience. Some readers may raise question at this point: what is new here? It seems similar with Freud's id-egosuperego model.

Let us answer such a question: No, it is really in contrast with Freud's model which is purely materialistic in origin. The notion of spirit is rejected in Freud's model.

More note on the terms used here may be useful for readers. We don't attempt to just alter the term from superego with spirit, in fact we don't think that superego does exist. It is human spirit which governs the whole human consciousness. And human spirit is

\footnotetext{
${ }^{190}$ As a simple introduction to Neutrosophic Logic, allow us to quote from ref. [3]: "Neutrosophic Logic (NL) is a Theory of Everything in logics, since it is the most general so far. In the Neutrosophic Propositional Calculus a neutrosophic proposition has the truth value (T, I, F), where T is the degree of truth, I is the degree of indeterminacy (or neutral, i.e. neither truth nor falsehood), and F is the degree of falsehood, where T, I, F standard or non-standard subsets of the non-standard unit interval ]-0, 1+[. In addition, these values may vary over time, space, hidden parameters, etc. Therefore, NL is a triple-infinite logic but, by splitting the Indeterminacy, we prove in this article that $\mathrm{NL}$ is a $\mathrm{n}$-infinite logic, with $\mathrm{n}=1,2,3,4,5,6, \ldots$. The neutrosophic component of Indeterminacy can be split into more subcategories, for example Belnap split Indeterminacy into: the paradox $(\langle A\rangle$ and $\langle$ anti-A $\rangle)$ and uncertainty $(\langle A\rangle$ or $\langle$ anti-A $\rangle)$, while truth would be $\langle\mathrm{A}\rangle$, and falsehood $\langle$ anti-A $\rangle$. This way Belnap got his four-valued logic. In neutrosophy we can combine $\langle A\rangle$ and $\langle$ non-A $\rangle$, getting a degree of $\langle\mathrm{A}\rangle$ a degree of $\langle$ neut-A $\rangle$ and a degree of $\langle$ anti-A $\rangle$. $\langle\mathrm{A}\rangle$ actually gives birth to <antiA> and <neut-A>.

191 This model may be compared to Jung's personality model, which includes individual unconscious and collective unconscious.
} 
influenced by the Holy Spirit, if he/she is a believer. That is how our consciousness model is really different from Freudian mental model.

What we propose here may be called pneumatic-transpersonal psychology:

"Transpersonal psychology is a sub-field or "school" of psychology that integrates the spiritual and transcendent aspects of the human experience with the framework of modern psychology. It is also possible to define it as a "spiritual psychology."192

An interesting argument spiritual psychology has been discussed in Santa Monica site:

"If you look up the word "psyche" in the dictionary, you will find "breath, principle of life, Soul." But if you look up "psychology," you will find "the science of mind and behavior." Somehow, in the translation from essence to practice, the most important aspect of "psyche" has been lost. At the University of Santa Monica, we recognize our task as reintegrating the spiritual dimension back into the essence of an authentic psychological inquiry. It is this reintegration that evokes the emergence of a Spiritual Psychology.

Spiritual Psychology is the study and practice of the art and science of Conscious Awakening. To engage in this genre, we must begin by distinguishing the essence of human evolution - what does it mean to evolve? In short, it means learning how to identify, recognize, and navigate successfully within the Context of Spiritual Reality. Practically, it means learning how to surrender-or let go of-anything that disturbs one's peace. It also means sacrificing our illusions of separation. Essentially, this "surrendering" and "sacrificing" is work that can and has been called "healing," which includes healing on the physical, mental, and emotional levels in service to the deeper revelation of who we truly are as Loving, Peaceful, Compassionate, and Joyful beings. We refer to this level of awareness as the Authentic Self." 193

Columbia University also offers SMBI degree (spirituality, mind, body institute), which is "an interdisciplinary approach to learning, in which students explore multiple paradigms - neuroscience, spiritual psychology, innovative and ancient healing practices, inspired creativity and the arts, visionary education and social entrepreneurship — in service of the creation of a society rooted in spiritual values."194 In the last few days, we begin considering a further improvement of our model: from triune model to become quadruple model, by introducing the notion of "soul."

\footnotetext{
192 https://psychcentral.com/blog/6-facts-about-transpersonal-psychology/

$193 \mathrm{https} / / /$ www.universityofsantamonica.edu/why-usm/spiritual-psychology/

${ }^{194}$ https://www.tc.columbia.edu/counseling-and-clinical-psychology/smbi/
} 
Actually, the role of soul is immediate from the psychology term itself, although literally speaking "psyche" in Greek can mean mind, soul or spirit. (We know, that there is specific Greek word for spirit: pneuma).

According to Neal Goldsmith:

"The word psychology comes from the Greek psukhe, meaning "soul," "spirit," "mind," "life," and "breath," combined with the Greek logos, here used as "statement," "expression," and "discourse," more often thought of today in the form of "-ology," as "the study of." Although the academic and clinical discipline of psychology has become a medical-and therefore a pathology-oriented-field, prior to the late 1800s, the study of our inner mental life was the study of our soul, our deepest self or essence."[39]

However, Jung himself carefully distinguishes between psyche and soul, as it is clear that in German, the word "seele" can mean both: psyche and soul.

"I have been compelled, in my investigations into the structure of the unconscious, to make a conceptual distinction between soul and psyche. By psyche, I understand the totality of all psychic processes, conscious as well as unconscious. By soul, on the other hand, I understand a clearly demarcated functional complex that can best be described as a "personality". (Jung, 1971: Def. 48 par. 797)

[The translation of the German word Seele presents almost insuperable difficulties on account of the lack of an English equivalent and because it combines the two words "psyche" and "soul" in a way not altogether familiar to the English reader. For this reason some comment by the Editors will not be out of place.] [In previous translations, and in this one as well, psyche-for which Jung in the German original uses either Psyche or Seele-has been used with reference to the totality of all psychic processes (cf. Jung, Psychological Types, Def. 48); i.e., it is a comprehensive term. Soul, on the other hand, as used in the technical terminology of analytical psychology, is more restricted in meaning and refers to a "function complex" or partial personality and never to the whole psyche. It is often applied specifically to "anima" and "animus"; e.g., in this connection it is used in the composite word "soul-image" (Seelenbild). This conception of the soul is more primitive than the Christian one with which the reader is likely to be more familiar. In its Christian context it refers to "the transcendental energy in man" and "the spiritual part of man considered in its moral aspect or in relation to God." ... — Editors.] (Jung, 1968: note 2 par. 9)" [40]

Therefore, although we don't wish to complicate the matters, we come to this understanding: to study human consciousness in depth, we need to consider the four elements: mind, body, soul, spirit. We call it an integral model of human consciousness. A simplified diagram can be used to represent our integral model: 


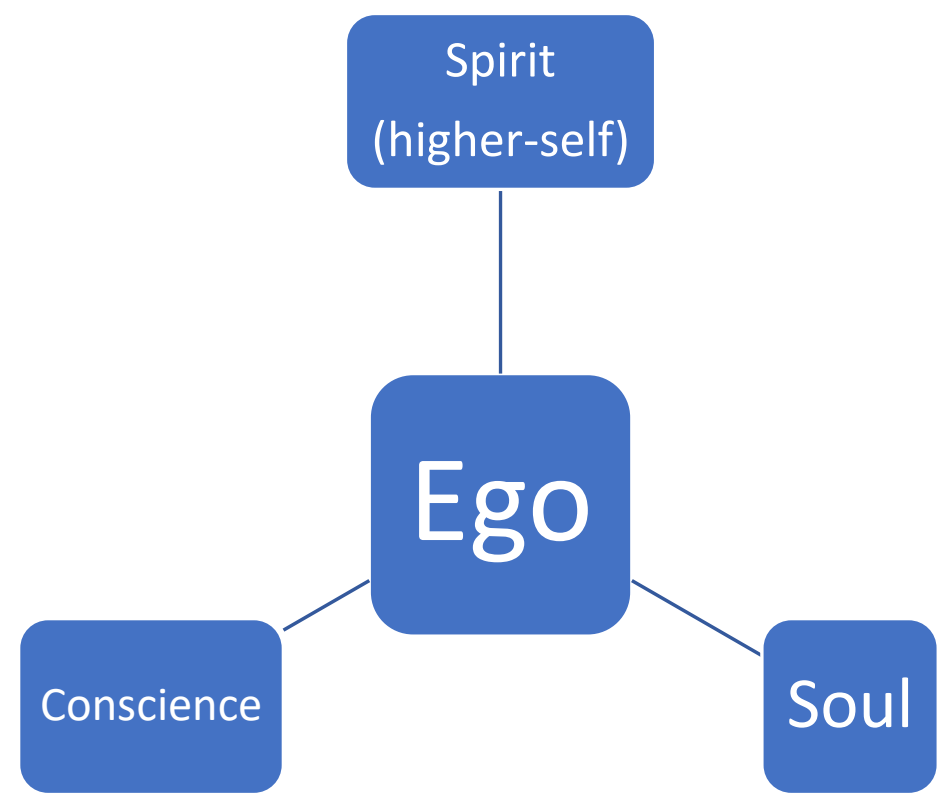

Figure 5. An integral model of human consciousness inspired by the Greatest Commandments in Matthew 22:37-40.

We are aware that our model is far from complete, and we intend to develop this model further later.

Nonetheless, one characteristics of our model is that the four elements are always in constant communications (dialog) among themselves, that is why we prefer to call this model: A relational quadruple model of human consciousness. If we are allowed to borrow a term from Trinitarian theology discourse: "perichoresis." In other words, we believe that human being was created to be in close relationship with the Great Dance of The Trinity. See for instance [41].

Now, readers may ask: what about the name of our model: following Jung's lecture to emphasize the four-fold as a basic requirement of completeness:

"Ancient Greek philosophy used quaternarian thinking. For Pythagoras, not three but four played the major role as, for example, in the so-called Pythagorean Oath. There it is said of the number four, the tetraktys, that "it has the roots of eternal Nature." Also in the Pythagorean school the opinion reigned that the soul was not a triangle, but a quadrangle. The origin of these views lies somewhere in the dark prehistory of the Hellenistic spirit. The quaternity is an archetype that occurs universally. 
Four is the logical prerequisite for every determination of totality. If one wants to make such a determination, it must have a fourfold aspect. If, for example, one wants to designate the totality of the horizon, one names the four cardinal points..."[42]

Therefore we would propose to call this model: quadruple Neutrosophic Psychology model of human consciousness.

\section{Introduction to Relational Therapy or the healing effect of compassion-love}

Nelson Mandela once remarked: "Our human compassion binds us the one to the othernot in pity or patronizingly, but as human beings who have learnt how to turn our common suffering into hope for the future."

Yes, we can accept his remark, but how to speak of compassion in terms of cancer treatment. Is there healing effect of compassion and love? We will take a deeper look into these questions in this section, which discussion allow us to submit a new method called: Relational Therapy.

First of all, let us admit that although a growing body of evidence suggests that giving to (helping) others is linked reliably to better health and longevity to the helper, the mechanism remains a mystery. However, there are recent papers which seem to support such a wide-held belief, see for instance [7].

Other research also suggests the neuroscience effect of pro-social behavior.[8]. A recent book by Adam Grant from Wharton also reveals on how giving to others may lead to better and happier life. [10]

Key ideas of Adam Grant can be summarized as follows:

"Depending on the situation, people can adopt different behaviors - they can take, give, or exchange. But usually, everyone has a dominant model that determines their behavior. All three models have their advantages and disadvantages. However, the author believes, and his view is supported by real-life experiences that givers receive fewer benefits, as they are guided by the interests of others and forget about their own interests. The link between giving and positive emotion is a cornerstone of Positive Psychology. Giving makes us happy. Studies have shown when subjects are given $\$ 5$ with instructions to give the money to a stranger, their happiness increases more than subjects who are given $\$ 20$ to spend on themselves (Dunn et.al. 2008)."[10] 
And a significant work in this direction of research has been written: "The compassion connection."[9]. Preface of their book begins with these words:

"As human beings, we are born with an innate and nearly limitless capacity for caring and compassion. We recognize when others around us are hurting; as the latest neuroscience has shown, we quite literally feel their pain-imaging studies have demonstrated that the same networks in the brain are activated whether people receive a painful stimulus themselves or are merely witnessing someone else receiving it. And we want to help. In fact, the human brain is actually wired for cooperation and giving. But we're not always good at it. We say the wrong things, or we zero in on the wrong problems. Often we manage to do more harm than good, causing hurt feelings and even damaging relationships. But there is another way. In The Compassionate Connection: The Healing Power of Empathy and Mindful Listening, I explain that we all have the astounding ability to help others in a way that prompts their healing from within and strengthens our bonds with them-while doing emotional and physical good for ourselves in the process. Indeed, some social psychologists have theorized that giving may enhance the giver's self-interest more than receiving. This is a two-way street."[9]

The author also tells:

"I learned the importance of the therapeutic ceremony and how the actual process of delivering care can dramatically enhance the effectiveness of what is prescribed. Research now shows how this is possible-that is, how personal interactions can actually have physiological effects on patients."[9]

In fact, that corresponds to the definition of integrative medicine:

"According to the Academic Consortium for Integrative Medicine and Health, it "reaffirms importance of the relationship between practitioner and patient, focuses on the whole person, is informed by evidence, and makes use of all appropriate therapeutic and lifestyle approaches, healthcare and disciplines to achieve optimal health and healing." 6 Much of the information I had absorbed during my fellowship constellated around how to stimulate self-healing mechanisms within my patients' bodies. This is part of what I like to think of as the "mystery and awe" of medicine." [9]

That is what we argue in this section, that caring and compassion through authentic relationship can lead to self-healing process. That is why we call it: "Relational therapy," to emphasize the role of loving in healing, just as we heard numerous times in Greatest Commandments as quoted above.

While we are aware that the ideas presented here may be not complete yet, but we are convinced that these ideas of authentic relationship, caring and compassion are supported by solid body of evidence. And they may hold the key to autoimmunity 
system of human body. Again, love and self are inseparable. In other words, a man or woman who do not want to care and practice compassion towards other people, we cannot call them just "selfish", instead they are "selfless" - i.e. they are losing the meaning of being a human.

This paper is an outline, or result of early investigation on how we can integrate human spirit into consciousness model. This is our response as theologian to psychology field [43]. While we are aware that the ideas presented here may be not complete yet, but we are convinced that these ideas of authentic relationship, caring and compassion are supported by solid body of evidence. Our proposition on the significant role of relational love is inspired by Sutton and Mittelstadt [44] and also Martin Buber's dialogue philosophy.

Enough with some basic principles, in the next sections we will discuss few applications of these concepts: Relational Psychotherapy and Relational Pedagogy.

Part B: A few applications

\section{Introducing Relational Psychotherapy}

First of all, let's ask a basic question: what constitutes a good therapy session? A long series of discussion, where the patient should recover his/her early childhood traumas? Or a more direct approach called Cognitive Behavioral Therapy?

Let us start with a joke:

Joe has been seeing a psychoanalyst for four years for treatment of the fear that he had monsters under his bed. It had been years since he had gotten a good night's sleep. Furthermore, his progress was very poor, and he knew it. So, one day he stops seeing the psychoanalyst and decides to try something different.

A few weeks later, Joe's former psychoanalyst meets his old client in the supermarket, and is surprised to find him looking well-rested, energetic, and cheerful. "Doc!" Joe says, "It's amazing! I'm cured!" "That's great news!" the psychoanalyst says. "you seem to be doing much better. 
How?"

"I went to see another doctor," Joe says enthusiastically, "and he cured me in just

ONE session!"

"One?!" the psychoanalyst asks incredulously.

"Yeah," continues Joe, "my new doctor is a behaviorist."

"A behaviorist?" the psychoanalyst asks. "How did he cure you in one session?"

"Oh, easy," says Joe. "He told me to cut the legs off of my bed."195

Some other known approaches are called Gestalt Therapy which corresponds to Logotherapy. According to common practice, gestalt therapy emphasizes the therapeutic relationship between client-therapist:

"Gestalt therapy is practiced in the form of exercise and experiments. It can be administered in individual or group settings. In general, exercises are somewhat established practices in gestalt therapy designed to arouse action, emotion, or goals from the person in therapy. The therapist and person in therapy can then examine the result of the exercise in order to increase awareness and help the person understand the "here and now" of the experience.

In contrast to exercises, experiments arise throughout the development of the therapeutic process and therapeutic relationship. They are a core component of gestalt therapy and allow the person in therapy to understand different aspects of a conflict, experience, or mental health issue.

The empty chair technique is a quintessential gestalt therapy exercise that places the person in therapy across from an empty chair. He or she is asked to imagine that someone (such as a boss, spouse, or relative), they, or a part of themselves is sitting in the chair. The therapist encourages dialogue between the empty chair and person in therapy in order to engage the person's thoughts, emotions, and behaviors. Sometimes the roles are reversed and the person in therapy assumes the metaphorical person or part of a person in the chair. The empty chair technique can be especially useful for helping people become mindful of the whole situation and forgotten or disengaged pieces of their own self." 196

What we would emphasize here is the "therapeutic relationship" phrase. We just realize that what's important is not just relationship between client-therapist per se, but also between client and his/her family, his/her friends, etc. In other words, we believe that

195 http://www.workjoke.com/psychologists-and-psychiatrists-jokes.html

196 https://www.goodtherapy.org/learn-about-therapy/types/gestalt-therapy 
human being is created to be woven into his/her social fabric, and most of the time this can have a healing effect.

According to Kathryn Stauffer et al:

"Traditionally, the field of psychotherapy, including psychoanalysis, has been fragmented and riddled with factions and specialities and different modalities. This has always left both users and referrers with a bewildering variety of therapies and with the question: which is the most effective for making clients better? There have been many attempts to answer this question, and many serious researchers have studied a variety of outcomes. Every first-year student knows that pretty much all of these studies have yielded the one answer: It's All In The Relationship. Psychotherapy modalities appear to be more or less equally effective, and clients working with therapists from different modalities emphasize that the therapeutic relationship has been the main factor that made a difference to their wellbeing. ... The term Relational Psychotherapy, in the way it is understood nowadays, was first used in the US by Greenberg and Mitchell in 19831, and they saw it as a bridge between the traditions of interpersonal relations and object relations. For relational theorists, mind always emerges and develops in the context of interpersonal relationships. In their view, our internal world acts as a kind of filter through which we experience ourselves and the world around us. It arises out of external experience by a process of internalisation. This filter helps us to function in the world, but it is also a limitation, especially if the experience it was built from originally was limited or damaging. Such a 'bad' early experience will then lead to a compulsion to re-enact it in an effort to try and make it better. Forming relationships with others offers us an opportunity to widen our perspective by giving us a deeper sense of our own and the other's humanity, and this experience can enable us to transcend our early introjects."[18]

There is deep truth behind a famous saying by Malcolm X:

“"When I is Replaced by We, Illness Becomes Wellness!"197

While we don't see this is an entirely new to psychotherapy, our proposed method is to begin with Martin Buber's famous philosophy: "I and Thou," where he emphasizes the significant role of dialogic-communications. And that is why we consider relational psychotherapy is more related to Buberian philosophy. See also [19]

${ }^{197}$ https://www.epicexperience.org/when-i-is-replaced-by-we-illness-becomes-wellness/ 


\section{Introducing Relational Pedagogy}

A definition of pedagogy tells us:

"The method and practice of teaching, especially as an academic subject or theoretical concept."198

And its origin goes back to $16^{\text {th }}$ century:

"Late 16th century: from French pédagogie, from Greek paidagōgia 'office of a pedagogue', from paidagōgos (see pedagogue)."199

But we can also ask: what constitutes a good pedagogy? That would require a whole bunch of academic papers.

We shall admit that we are not specialists in education/pedagogy theories. But long time ago, one of us (VC) read a famous book at the time by Paolo Freire, "Pedagogy of the oppressed." Freire has a reputation as an education philosopher which brought him to do join work with many organizations, including the World Council of Churches. One word that we learned from Freire is the significance of "conscientization." According to Arthur Lloyd:

"Paulo Freire, Brazilian educator, has elaborated an educational theory within the framework of a theory of radical social change and expressed in a literacy training program. A central concept is "conscientization," and development of critical consciousness through a process of reflection and action."[20]

While we are not so much in agreement with his post-marxian approach, we accept that conscientization is very important aspect in education. But not only that, a good educator should also give special attention to teach his/her students on how to respect and accept the others (that need a dialogic view), to communicate, to cooperate, and to have compassion. In our opinion, such a set of new soft skills are very important especially in the light of the rise of digital networks, which imply that anyone connected to digital networks will be exposed to numerous expressions of cultural and philosophical differences. Therefore, all these skills become conditio sine qua non in this digital and social media age.

We consider that Martin Buber's dialogic philosophy can be useful for this goal too, which leads us to consider "Relational Pedagogy." The good news here is that such an

\footnotetext{
198 https://en.oxforddictionaries.com/definition/pedagogy
}

${ }^{199} \mathrm{https} / / / \mathrm{en} .0 x$ forddictionaries.com/definition/pedagogy 
idea "Relational Pedagogy" has been discussed for some years by a number of academicians. See [22][23][24][25].

\section{Concluding remarks}

As an extension of one of us's book: Neutrosophic Psychology, in this paper we consider the following: that human consciousness model should take into consideration "spirit" role, i.e. the mind-body-spirit as integral aspect, which view is neglected in the so-called Freudian mental model.

In this paper, we also consider a few applications derived from such an integral quadruple view of human consciousness, including Relational Psychotherapy and Relational Pedagogy.

This paper is an outline, or result of early investigation on how we can integrate human spirit into consciousness model. This is our response as theologian to psychology field [43]. While we are aware that the ideas presented here may be not complete yet, but we are convinced that these ideas of authentic relationship, caring and compassion are supported by solid body of evidence. Our proposition on the significant role of relational love is inspired by Sutton and Mittelstadt [44] and also Martin Buber's dialogue philosophy.

To summarize key ideas in this paper, instead of repeating the Cartesian old adage: cogito ergo sum (I think therefore I am), probably it is much better to consider a new phrase: I love therefore I am (we are not sure about Latin version, may be something like this: "Amo cogito ergo sum.")

\section{Acknowledgement}

One of us (VC) would like to express his gratitude to a reviewer for his comments. This paper is dedicated to Jesus Christ who always encouraged and empowered him in many occasions. He is the Good Shepherd. Soli Deo Gloria! 
Document history:

Ver. 1.0. $20^{\text {th }}$ October 2018, pk. 12:24

Ver 1.1: $22^{\text {nd }}$ October 2018, pk. 18:39

Ver 1.2: $24^{\text {th }}$ October 2018, pk. 6:53

Ver. $1.3: 15^{\text {th }}$ june 2019 , pk. $16: 12$

$\mathrm{VC} \& \mathrm{FS}$

\section{References:}

[1] V. Christianto \& F. Smarandache. The world within us: (or: A sketch of consciousness space beyond Freudian mental model and implications to socio-economics modeling and integrative cancer therapy). BAOJ Cancer research, Sept. 2018.

[2] F. Smarandache. Neutrosophic Logic - A Generalization of the Intuitionistic Fuzzy Logic (2003). url: https://arxiv.org/ftp/math/papers/0303/0303009.pdf

[3] F. Smarandache. Neutrosophic Logic as a Theory of Everything in Logics. (2010). url: http://www.rxiv.org/pdf/1004.0024v1.pdf

[4] D. Martin Lloyd-Jones. Healing and the Scriptures. Published in Nashville, Tennessee, by OliverNelson Books, a division of Thomas Nelson, Inc., Publisher, 1988.

[5] David R. Hawkins. Power vs. Force: The Hidden Determinants of Human Behavior. The Institute for Advanced Theoretical Research, 1995. url: https://www.amazon.com/Power-vs-Force-

Determinants-Behavior-ebook/dp/B00EJBABS2

[6] David Hawkins. Scale of consciousness. url: www.freedomwithin.org

[7] Stephanie Brown and R. Michael Brown. Connecting prosocial behavior to physical health.

Neuroscience and Biobehavioral Review, 55 (2015) 1-17

[8] Alexander Easton \& Nathan Emery. The cognitive Neuroscience and Social behaviour.

Psychology Press, 2005, 270 Madison Avenue, New York, NY 1001

[9] David Rakel \& Susan K. Golant. THE COMPASSIONATE CONNECTION. The Healing Power of Empathy and Mindful Listening. London: W.W. Norton \& Company

[10] Adam Grant. Give and Take. https://positivepsychologyprogram.com/adam-grant-give-and-take/

[11] Vibrational Frequency of human organs as discovered by Bruce Tainio. url:

http://justalist.blogspot.com/2008/03/vibrational-frequency-list.html

[12] An article extracted from the book 'The Cancer Cure That Worked' by Barry Lynes (Marcus

Books), later published in Nexus Oct-Nov 93. url:

https://www.frequencyrising.com/rifemachine_cancercure.html

[13] Splagchizomai. url: https://www.lifefm.co.nz/more/word-for-you-today/item/2788-

$\% 27$ splagchnizomai\%27-

[14] Verbs That Make All the Difference in the World: Splagchnizomai. Url:

https://www.theologyofwork.org/the-high-calling/daily-reflection/verbs-make-all-difference-worldsplagchnizomai

[15] Mark Mayberry. Compassion. url: http://markmayberry.net/wp-content/uploads/biblestudy/2007-09-09-am-MM-Compassion-Long.pdf

[16] Moved with compassion. Url: https://pastorsavage.net/2018/03/08/moved-with-compassion/ 
[17] Florentin Smarandache, Neutropsychic Personality, a mathematical approach to psychology, Pons asbl, Belgium, first edition 118 pages, 2018; second enlarged edition, 131 p., 2018.

[18] Kathrin Stauffer, Liora Medina, and Dianne Chipperfield. Relational Psychotherapy and the Wounded Healer. An Invitation to the CABP Conference 'The Client and I: Relational Dilemmas and Opportunities in Psychotherapy'. url:

http://www.moaiku.dk/moaikuenglish/englishlitterature/articles_pdf/a4/relational.pdf

[19] Paul L. Wachtel. An Integrative Relational Point of View. Psychotherapy 2014, Vol. 51, No. 3 , 342-349. American Psychological Association. url: https://www.apa.org/pubs/journals/features/psta0037219.pdf

[20] Arthur S. Lloyd. Freire, Conscientization, and Adult Education.

journals.sagepub.com/doi/10.1177/074171367202300101

[21] G. Sabto. Paulo Freire: conscientization, the road to freedom. Url: https://minervaaccess.unimelb.edu.au/handle/11343/114630

[22] J. Aspelin. Co-Existence and Co-Operation: The Two-Dimensional Conception of Education. Education: 2011; 1(1): 1-6 DOI: 10.5923/j.edu.20110101.04

[23] J. Aspelin. How Do Relationships Influence Student Achievement? Understanding Student Performance from a General, Social Psychological Standpoint. International Studies in Sociology of Education, March 2012

[24] J. Aspelin. Relational Pedagogy and Teachers’ Relational Competence. Konference Relationskompetencer $i$ skolen og laereruddannelsen.

[25] Alex Guilherme \& W. John Morgan. Martin Buber's philosophy of education and its implications for adult non-formal education. International Journal of Lifelong Education, 28:5,565 — 58

[26] Annie Ó. Breacháin. Mind-bodies, Interdependent Opposites and Knots: A Phenomenological Inquiry into the Child-Teacher Relationship in Upper Primary School. PhD dissertation, University of Exeter. 2016

[27] Rezvan Shahsavari-Googhari. How Do Teachers Challenge Neoliberalism Through Critical Pedagogy Within and Outside of the Classroom? thesis submitted in partial fulfillment of the requirements for the degree in Master of Arts, august 2017, The University of Western Ontario. Electronic Thesis and Dissertation Repository. 4760. https://ir.lib.uwo.ca/etd/4760

[28] Adam Grant. Give and Take. Url: https://psychcentral.com/lib/give-take-a-revolutionaryapproach-to-success/

[29] https://bpicampus.com/2013/04/27/morning-feature-give-and-take-part-iii-changing-culturesnon-cynical-saturday/

[30] Lone Hersted \& Kenneth J. Gergen. Relational Leading. Url: https://www.pdf.net/assets/uploads/publications/Relational\%20LeadingTxt_SAMPLE_chp1.pdf

[31] Lone Hersted \& Kenneth J. Gergen. Developing leadership as dialogical practice. url:https://www.researchgate.net/publication/304747466_Developing_leadership_as_dialogic_practic $\mathrm{e}$

[32] Syvanen Syrpa. Dialogic Leadership. url:

http://www.uta.fi/jkk/dinno/aineisto/SyvanenTikkamaki.pdf 
[33] Syvanen Sirpa \& Sari Tapura. Nordic management and organization now and future. Url: http://www.uta.fi/yky/en/contact/personnel/sirpasyvanen/index/Dialogic\%20leadership\%20of\%20cre ativity.pdf

[34] Rens van Loon. Dialogical Leader. Deloitte. url: http://www.dialogical-leader.com/wpcontent/uploads/2011/06/dialogical-leader-version-3.9.102.pdf

[35] Paul Brown, Malcolm B. Macmillan, Russel Meares, Onno Van der Hart. Janet and Freud: revealing the roots of dynamic psychiatry. Australian and New Zealand Journal of Psychiatry 1996; 30:480-491

[36] ONNO VAN DER HART, PAUL BROWN AND BESSEL A. VAN DER KOLK. Pierre Janet's Treatment of Post-traumatic Stress. Journal of Traumatic Stress, Vol 2, No. 4, 1989.

[37] ONNO VAN DER HART AND RUTGER HORST. The Dissociation Theory of Pierre Janet. Journal of Traumatic Stress, Vol 2, No. 4, 1989

[38] M. Rosselli \& D. Vanni. ROBERTO ASSAGIOLI AND CARL GUSTAV JUNG. The Journal of Transpersonal Psychology, 2014, Vol. 46, No. 1. Url:

https://pdfs.semanticscholar.org/27aa/c73e92e2e37223dad7366e321b28777e2fb2.pdf

[39] Neal M. Goldsmith. Psychology: the study of soul? Psychology Today, url: https://www.psychologytoday.com/us/blog/psychedelic-healing/201011/psychology-the-study-thesoul

[40] https://en.wikipedia.org/wiki/Psyche_(psychology)

[41] Baxter Kruger. The Great Dance. url: ftp://ftp.compuconference.com/Christian_Material/etext/Perichoresis/the\%20Great\%20Dance.pdf

[42] Carl G. Jung. On the Psychology of the Concept of the Trinity. Originally published in Quadrant, XXVIII:1, Winter 1998. url: http://www.cgjungpage.org/learn/articles/analytical-psychology/184-onthe-psychology-of-the-concept-of-the-trinity

[43] Michael Utsch. The Challenge of Psychotherapy for Religion and Spirituality. Psyche \& Geloof 18 (2007), nr. 1-2, page. 86-95

[44] Geoffery W. Sutton \& Martin W. Mittelstadt. Loving God and Loving Others: Learning About Love From Psychological Science and Pentecostal Perspectives. Journal of Psychology and Christianity 2012, Vol. 31, No. 2, 157-166

About the authors:

Victor Christianto completed graduate theology program at STT Satyabhakti, Malang. Nowadays he teaches at STT Satyabhakti Jakarta, and also as a member of editorial team of Jurnal Teologi Amreta. url: www.sci4God.com. E-mail: victorchristianto@gmail.com Florentin Smarandache is a full professor of mathematics at University of New Mexico, Gallup - USA. He developed Neutrosophic Logic theory as an extension of Lotfi Zadeh's fuzzy logic. url: http://fs.unm.edu 